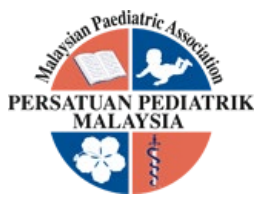

\title{
THALASSAEMIA CARE IN TERENGGANU - A LOCAL REPORT
}

\author{
Nazzlin Dizana Din
}

\begin{abstract}
Inherited thalassaemia disease is commonly found in many countries of the world. Care of the disease requires comprehensive management strategies comprising of clinical management of both transfusion dependant thalassaemia (TDT) and non-transfusion dependant thalassaemia (NTDT). It also includes preventive measures such as screening programmes and genetic counseling in order to contain the genetic transmission. At the moment, the only cure is through haematopoeitic stem cell transplant (HSCT). This report illustrates thalassaemia disease prevalence in the Terengganu state and the evolution of care since National Thalassaemia Programme was launched in 2009.
\end{abstract}

Keywords: Thalassaemia care, Terengganu, Malaysia, Transfusion dependant thalassaemia, National Thalassaemia Programme

\section{Introduction}

Thalassaemia disease is well known to many parts of the world especially in the region of "thalassaemia belt" which stretches from Mediterranean countries going through subSaharan Africa and Middle East to South and South East Asia including Malaysia [1]. It is estimated that less than $5 \%$ of the world population has the defective thalassaemia gene [2]. Depending on certain factors, the clinical presentation range from non-transfusion/infrequent transfusion disease to a total transfusion dependant thalassaemia (TDT). Comparatively, the latter type confers a much predicted morbidities \& mortality from the iron loading as a result of regular blood transfusion.

Here, we would like to report the local disease burden in the state of Terengganu and the current status of the management care in reflecting the patients' care in the state.

\section{Epidemiology}

In Malaysia, $\mathrm{HbE}$ beta thalassaemia and beta thalassaemia major constitute the two major types of thalassaemia disease, comprising of $34.4 \%$ and
Received: 10 May 2020; Accepted revised manuscript: 14 July 2020

Published online: 28 July 2020
$33.5 \%$ respectively. Others are $\mathrm{HbH}$ disease $(18.3 \%)$, beta thalassaemia intermedia (9.3\%) and unspecified thalassaemia disease (4.5\%) made up the rest .However, in Terengganu, HbE beta thalassaemia made up the majority of the patients (52.3\%) while beta thalassaemia major and $\mathrm{HbH}$ disease; each has almost similar volume of patients (18\%) [3].

Among the states in Malaysia, thalassaemia patients in Terengganu constitutes close to $5 \%$ of the total thalassaemia patients in the country (Figure 1)[3]. For many years, Sabah has been having the highest density of thalassaemia patients $(22.7 \%)$ in the country, followed by Selangor (14.6\%) and Kedah (8.7\%). In comparison

\footnotetext{
Paediatric Department, Hospital Sultanah Nur Zahirah, Ministry of Health, Kuala Terengganu, Terengganu, Malaysia

Corresponding author: Dr Nazzlin Dizana Din. Paediatric Department, Hospital Sultanah Nur Zahirah, Ministry of Health, Kuala Terengganu, Terengganu. Tel: 609-6212121 ext:2097

Email: nazzlindizana@yahoo.com
} 


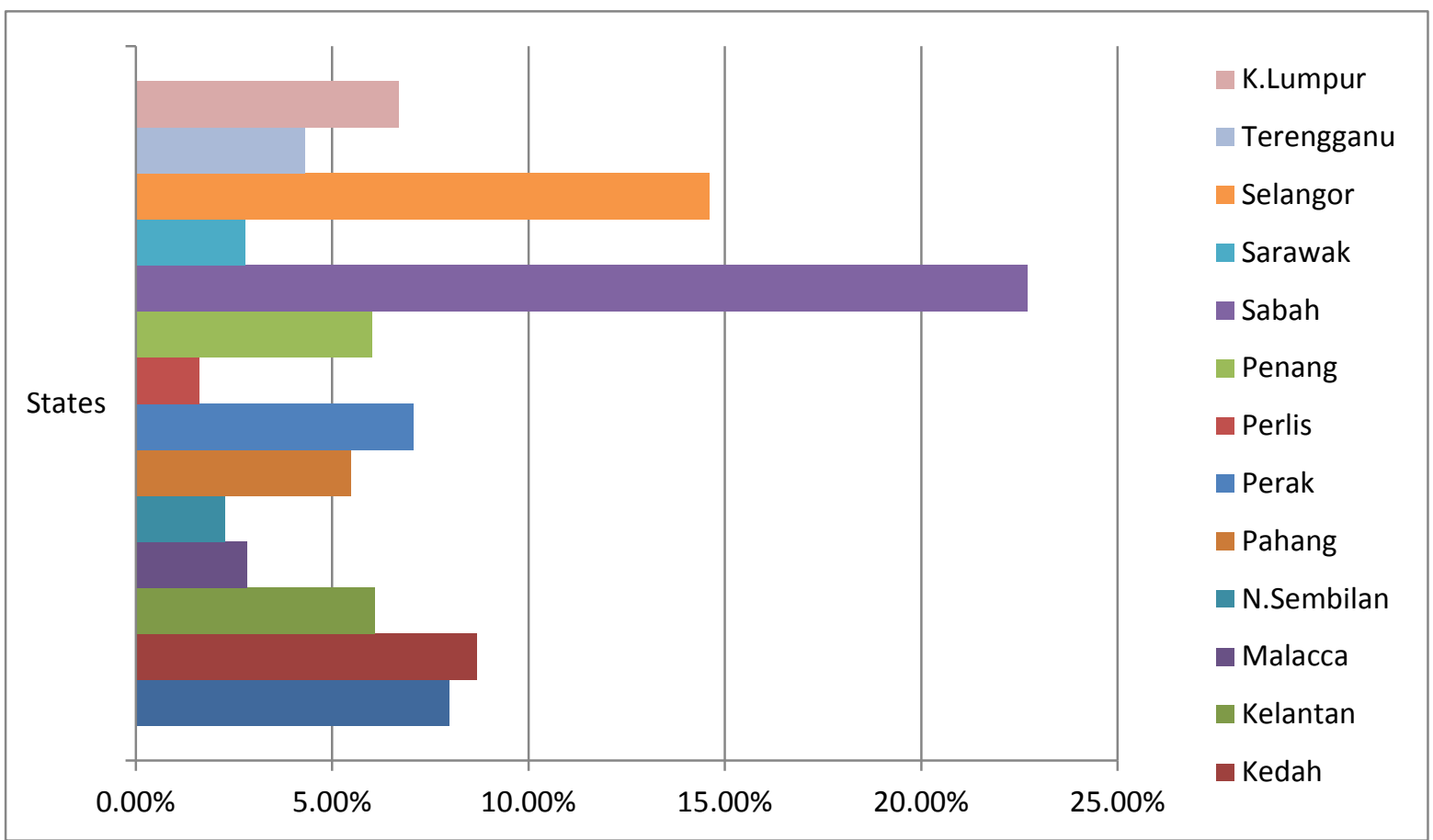

Figure 1. Thalassaemia population in Malaysia; represented in each state. Sabah and Selangor constituted the major bulk of the population.

to Sabah, Sarawak has much lesser number of patients (2.8\%) [3].

Since Kuala Terengganu is the major district in Terengganu, it has the largest number of thalassaemia patients, 225 (65.4\%). This is followed by Kemaman and Ulu Terengganu which shared almost the same number of patients, 32 (9.0\%) and 33 (9.6\%) respectively. Both Dungun and Besut also shared almost the same number of thalassaemia patients, $23(6.7 \%)$ and 24 (7.0\%) respectively while Setiu has the least number of patients, 8 (2.3\%) [3].

Unlike Hospital Sultanah Nur Zahirah (HSNZ) and Hospital Ulu Terengganu, other district hospitals do not have daycare facilities to cater the blood transfusion service. Therefore, these patients require admission to the ward for the purpose of blood transfusion. In the previous years, due to the unkempt technical process, patients would have to stay in the ward for 2-3 days just to get blood transfusion. However, since 2016, with good collaboration with the state blood bank and revised technicalities of the admission mechanism, the blood transfusion process in the ward has been made similar to the daycare concept. By doing so, a patient would have just to spend several hours in the ward during daytime for blood transfusion without an overnight stay.

\section{Disease Pattern}

In particular to the TDT patients, due to the high rate of iron loading secondary to regular blood transfusion, the other treatment instituted on the patients are iron chelation therapies. The chelating agents are to be taken consistently in order to ensure adequate chelation. Thus, long term morbidities such as cardiac dysfunction, diabetes mellitus, hypothyroidism, hypoparathyroidism and hypogonadism can be prevented. Mortality in TDT patients are mostly attributed to cardiac dysfunction. Similar to many parts of the world, three chelating agents are widely used in Malaysia which are desferrioxamine, deferiprone and deferasirox. Guided by certain factors such as age, cost or budget allocation and level of iron load, these agents are prescribed in accordance to the local guideline (2008 National Clinical Practice Guideline on Thalassaemia Management). Local 
data showed $99 \%$ of TDT patients in Terengganu have been prescribed with iron chelating agents.

With better availability of the iron chelating agents and increasing awareness regarding the thalassaemia management among doctors treating thalassaemia patients, their survival improved significantly in comparison to the previous two decades. Previously, there was only $25 \%$ of TDT patients who lived up to 25 years and beyond. However, at present, up to $60 \%$ of them are living to 40 years of age and beyond [3]. The eldest TDT patient in Terengganu was currently 62 years old.

\section{Iron Burden}

For more than four decades, serum ferritin has been a reliable indicator used to reflect iron load in thalassaemia patients. A level of more than $2500 \mathrm{mcg} / \mathrm{L}$ has been statistically proven to be associated with many complications of iron overload [4]. In addition to serum ferritin, a special imaging modality called magnetic resonance imaging (MRI) T2* has been used widely around the world as a tool to measure tissue iron in particular in the liver and in the heart. In Malaysia, the development of this imaging modality is slowly taking place in many major hospitals including HSNZ, Kuala Terengganu. The MRI T2* facility was first started in May 2016.
Our local data from 2015 to 2018 showed an increasing number of patients having serum ferritin less than $2500 \mathrm{mcg} / \mathrm{L}$ (Figure 2)[3]. The number has reached to almost two third of the total TDT patients in 2018. This is mainly contributed by a more structured comprehensive management across the state. A periodic counseling programme has been regularly conducted since 2016 focusing on the poor compliant patients.

Among 67 patients aged more than 10 years old who underwent MRI T2* procedures between 2016 and 2018 , majority (40\%) had severe form of liver siderosis. While patients with moderate and mild form made up the rest in equal numbers (30\%). In contrast, patients with severe cardiac siderosis only made up less than $5 \%$. About $70 \%$ of the patients did not have iron loading in their heart (Table 1). These basically signify that, in majority of these patients, their hearts are spared from being the sites of iron loading. Further exploration on this issue would be under-taken soon.

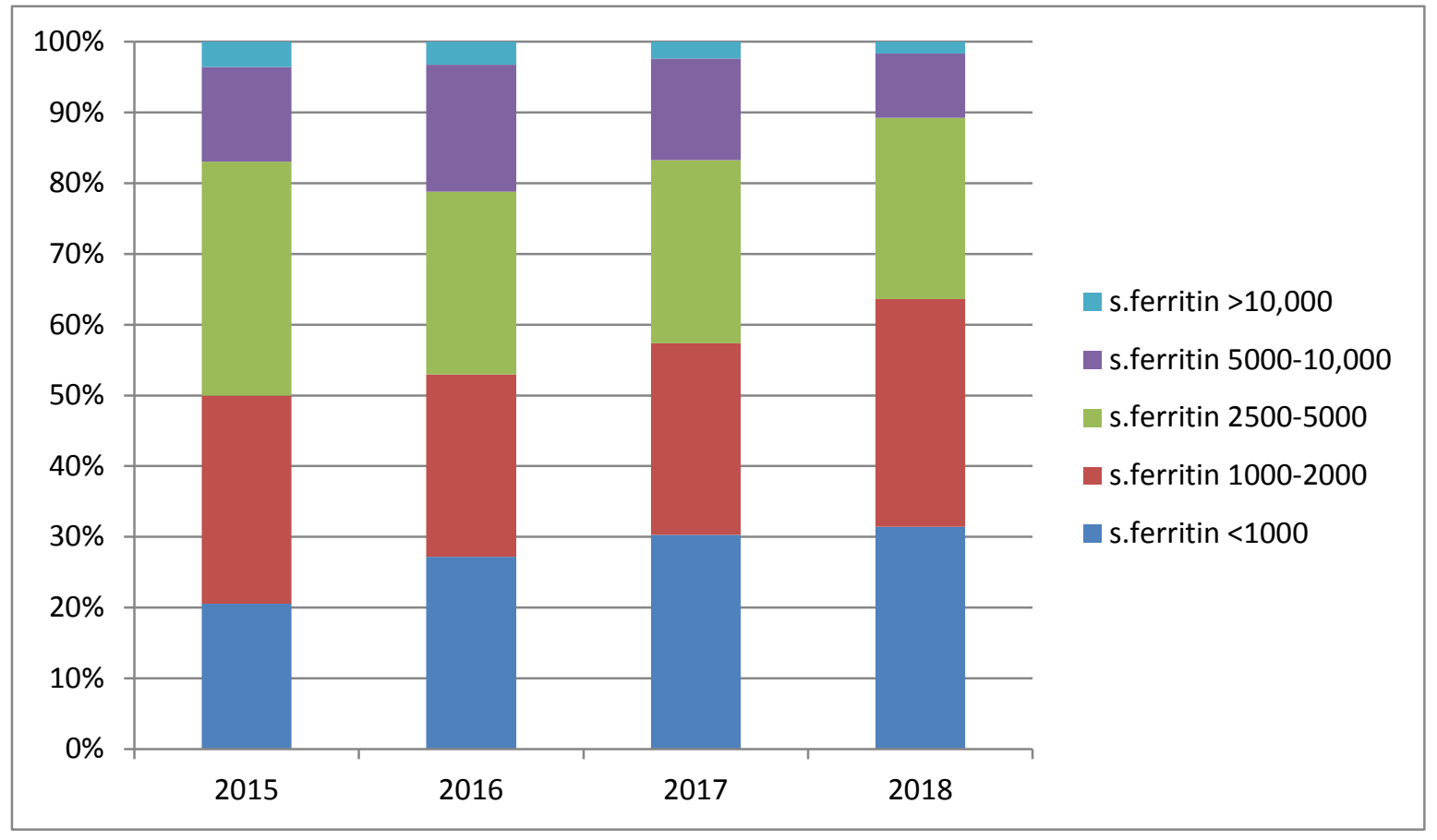

Figure 2. Percentage of TDT patients in Terengganu with their serum ferritin level. 
Table 1. MRI T2* Liver and Heart $(n=67)$

\begin{tabular}{|c|c|c|c|c|}
\hline & $\begin{array}{c}\text { Severe iron } \\
\text { loading (ms) } \\
\text { liver: }<2.1 \mathrm{~ms} \\
\text { heart: }<10 \mathrm{~ms}\end{array}$ & $\begin{array}{l}\text { Moderate iron } \\
\text { loading; (ms) } \\
\text { liver:2.1-4.5 ms } \\
\text { heart:10-14 ms }\end{array}$ & $\begin{array}{l}\text { Mild iron loading; } \\
\text { (ms) }\end{array}$ & $\begin{array}{c}\text { No iron loading (ms) } \\
\text { liver: }>15.4 \mathrm{~ms} \\
\text { heart: }>20 \mathrm{~ms}\end{array}$ \\
\hline Liver $(\mathrm{n}=67)$ & 27 & 20 & 20 & \\
\hline Heart $(n=67)$ & 3 & 1 & 11 & 52 \\
\hline
\end{tabular}

\section{Curative Treatment}

Until today, HSCT remains the option of cure. In Malaysia, when the treatment option was started since 1992, many thalassaemic patients in the country have been successfully cured with the procedure. In Terengganu however, the treatment option remained naïve to most of the patients and caretakers. It was not until 2017, parents of a TDT $\mathrm{HbE}$ beta patient were very much keen to have their daughter to undergo the HSCT procedure. Following the success of her HSCT, many parents started to enlist their thalassaemic children for the curative treatment. At the time of this article writing, three patients had successfully undergone the HSCT procedures and another two patients were waiting for their first HSCT appointment. The current recommendation of HSCT under Ministry of Health $(\mathrm{MOH})$ is to perform it at an early age or before complications of iron overload developed [5].

\section{Preventive Measures}

Since 2016, a significant decline in the number of thalassaemia new births has been noted (Table 2)[3]. Given the low level of awareness in the community, it is not known precisely, the cause of the drop in the thalassaemia new birth. Although the prenatal diagnosis have not been well accepted by many parents of the thalassaemic patients, many of these parents practice family planning especially after proper genetic counseling was given to them. Our observation showed many of these at risk parents stop conception following the thalassaemia diagnosis of their child. However, this may just contribute to a minor percentage of the drop.

The current thalassaemia population screening targeting form four students nationwide which was first initiated in 2016 has been showing satisfactory results of carrier rate detection at par with the global rate, $2-5 \%$. However, it is probably still early to speculate the secondary outcome of the screening programme that is to reduce the number of thalassaemia new birth.

Table 2. Number of new birth of thalassaemia in Terengganu.

\begin{tabular}{lllllll}
\hline & 2014 & 2015 & 2016 & 2017 & 2018 & 2019 \\
\hline $\begin{array}{l}\text { Thalassaemia } \\
\text { New Birth }\end{array}$ & 10 & 12 & 11 & 5 & 3 & 2 \\
\hline
\end{tabular}




\section{Current Management Strategy}

With increasing awareness about HSCT and its success in curing patients with thalassaemia disease, many parents start to pave their ways towards the treatment. This should be the way forward as part of the strategy to reduce the expansion of the thalassaemia population. It is hoped, the form four thalassaemia screening programme would further reduce the thalassaemia population size in the long term.

\section{Acknowledgement}

The author would like to thank the Director General of Health Malaysia for the permission to publish the paper.

\section{References}

[1] Weatherall DJ. The challenge of haemoglobinopathies in resource poorcountries. British Journal of Haematology. 2011; 154(6): 736-44.

[2] Taher AT, Weatherall DJ, Cappellini MD. Thalassaemia. The Lance.2018; 391(10116): 155-67.

[3] The Malaysian Thalassaemia Registry Report 2018

[4] Guidelines for the Management of Transfusion Dependant Thalassaemia (TDT);4th Edition, (Thalassaemia International Federation)

[5] Management of Transfusion Dependant Thalassaemia; Malaysia Clinical Practice Guidelines; 1st Edition November 2009 